\title{
The Individual Dimension of Digital Innovation: The Altered Roles of Innovation Agents and Market Actors
}

\author{
Haneen Allataifeh (1) and Sedigheh Moghavvemi * \\ Department of Operation and Management Information System, Faculty of Business and Accountancy, \\ University of Malaya, Kuala Lumpur 50603, Malaysia; haneenallataifeh@gmail.com \\ * Correspondence: sedigheh@um.edu.my; Tel.: +6-0379-973-831
}

Citation: Allataifeh, $\mathrm{H}$;

Moghavvemi, S. The Individual Dimension of Digital Innovation: The Altered Roles of Innovation Agents and Market Actors. Sustainability 2021, 13, 8971. https://doi.org/ $10.3390 /$ su13168971

Academic Editor: Uwe Riss

Received: 24 June 2021

Accepted: 6 August 2021

Published: 11 August 2021

Publisher's Note: MDPI stays neutral with regard to jurisdictional claims in published maps and institutional affiliations.

Copyright: (c) 2021 by the authors. Licensee MDPI, Basel, Switzerland. This article is an open access article distributed under the terms and conditions of the Creative Commons Attribution (CC BY) license (https:// creativecommons.org/licenses/by/ $4.0 /)$.

\begin{abstract}
Digital innovation entails the employment of new technologies to address business issues and to create practices that lead to the achievement of sustainability. It is observed that digital technology alters the individual dimension of the innovation process, allowing for a set of heterogenous actors to become active engagers in the process. A review of the previous research revealed a lack of focus on the roles these different actors play in the digital innovation process, as well as the mechanisms by which digital technology facilitates actor engagement, calling for research to shed some light on this topic. This phenomenological study undertakes an exploratory investigation of twenty-one Malaysian small- and medium-sized enterprises (SMEs) in the information and communication technology (ICT) sector, with the aim to demonstrate the importance of engaging market actors in each stage of the value co-creation process. Interviews with industry players show the shifted role of market actors in the innovation process-from product receivers to gatekeepers-at different stages of the innovation process. Market actors are extensively engaged in validating and evaluating the progress of ongoing digital innovation projects and, therefore, can modify their direction. Meanwhile, the role of innovation agents changes from an authoritative to reflective one. This study provides evidence that market actors are in a controlling position at certain points of the innovation process. As such, the view of the innovation process as being company-centric is challenged by the findings of this research. We provide new information regarding innovation practices, the roles of key actors, and their value in the digital context, which can serve as valuable knowledge for both academics and practitioners.
\end{abstract}

Keywords: digital innovation process; innovation collectives; market actors; Malaysian SMEs; ICT sector

\section{Introduction}

In its simplest form, digital innovation can be described as 'the carrying out of new combinations of digital and physical components to produce novel products' [1] (p. 725). Digital innovation has been viewed as a source of old business renewal, by combining traditional product elements with digital materiality [2,3]. Digital innovation processes have become more open and collaborative, with IT being a decisive enabler of collective innovation involving heterogeneous actors [4]. Due to such openness, several determinants influence digital innovation, which can be categorized into three dimensions: organizational, individual, and environmental. The organizational dimension covers organizational characteristics, such as resource allocation, structure, and strategy. The environmental dimension incorporates the organizational environment and the competitive landscape, while the individual dimension describes actors and their characterization [4].

At the individual level, two main actor groups can be distinguished: innovation agents, who are involved in the development process (i.e., companies), and market actors, who use digital innovation (i.e., customers and users) [4]. Nambisan et al. have explained that digital technology characteristics alter the degree and nature of innovation, regarding "who can 
participate (actors), what they can contribute (inputs/resources), how they can contribute (process/governance), and to what ends (outcomes/value)" [5] (p. 3). Scholarly work has found that digital characteristics influence how companies innovate, alter boundary relations, and boost platform thinking through affirming the significance of heterogeneous contributors, referred to as innovation collectives, who share diverse motives, capabilities, and goals [6].

Research on innovation collectives is ambiguous, rare, emerges as a side effect of addressing other areas, and the literature in this topic remains very superficial and generic. Only a few papers have covered the characteristics of actors in the digital innovation context [4], or investigated digital innovation from the perspective of innovation actors involved in the value co-creation process [7]. At the heart of innovation collectives, the market dimension is implicated, where market actors become core contributors to the process of digital innovation. However, managerial tools and academic conceptualizations have mainly focused on the technological dimension of digital innovation, at the cost of ignoring the market dimension of innovation collectives [4,8]. Consequently, a comprehensive understanding of innovation actors in a digital context is indispensable [4]. With this purpose in mind, this study focuses on innovation collectives and investigates the individual dimension of digital innovation, using the need-solution-coupling notion of von Hippel and von Krogh [9], in order to link innovation activities with the actions, behaviors, and needs of market actors.

From the perspective of innovation collectives, actors contributing to the development of digital innovation are spread between the company and its external environment. However, this research focuses on two main actors: innovation agents (i.e., companies) and market actors (i.e., customers and users). Market actors become involved in product development, and are no longer just passive buyers [10]. Despite acknowledgement of the need to engage market actors, the majority of scholars consider them as a source of data, instead of active engagers in the innovation process (see, e.g., [11]). Hence, little is known regarding the market dimension of digital innovation, despite its significance [7]. Ahmad and Looy [12] conducted a systematic literature review, and revealed that it is still unclear how customers interact and engage in the digital innovation process, as well as what role digital technology plays in this interaction.

To the best of our knowledge, there are no studies that have analyzed the various roles of market actors and innovation agents, or how their interaction is digitally enabled at stage-level in the digital innovation process. This study is, therefore, intended to fill a gap in the extant literature, targeting the ICT sector, which is highly sensitive to digitalization. This study contributes to the literature by providing additional knowledge on where and when in the innovation process market actors become involved, along with what role they play at each stage in the process, and how this role is enabled by digital technology. Therefore, this study explicates the individual dimension of digital innovation and extends the analysis of the market dimension from a limited view of customer information and user knowledge. The outcomes of this study challenge the conventional wisdom that innovation is an innovator-centric process, and elaborates on the various authoritative, controlling, and inspirational roles of market actors at different stages of the innovation process. This study elaborates the proposed ideas for further research on digital innovation as an entity at the crossroad of market and technology [13], and sets an integrative perspective to build upon in future research on digital innovation and its management.

To fill a gap in the literature, this study aims to answer the following questions: What roles do market actors play in developing digital innovation? How do those actors collaborate with innovation agents when developing digital innovation? And how does digital technology enable the innovation process to unfold, from a market actor-centric point of view?

In the following sections, we address the previous literature and research gaps, build the theoretical foundation, and discuss the research design, including the data analysis 
approach. Finally, the results of the data analysis, their discussion, our contributions, and the limitations of the study are presented

\section{Literature Review}

The usage of digital technology in innovation processes has not only changed products and services, but has also changed the scope, speed, and scale of the innovation process. Digitalization changes how companies capture and create value and cultivate innovation. The distinctive characteristic of digital technology improves the ability of innovation agents to sense and respond to opportunities, and increases both their explorative and exploitative capabilities [14]. Further, digital technology allows for the creation of new forms of agency, both within and across processes [1].

Digital technology has been found to alter the traditional linearity of innovation. Due to digital technology, it is less obvious as to where and when a specific stage of the digital innovation process begins and/or ends. The process evolves in a non-linear way through time and space, and a digital product is typically in a continuous state of incompleteness and emergence. Consequently, traditional innovation process logic, which focuses on generating a complete state of products to be launched into the market, conflicts with the logic of digital innovation, which is incomplete and emerges over time and space [13].

Digital innovation surpasses the mere alteration of technological artifacts to further considerations of the related socio-technical context, regarding the technology and its usage implications in business and society [13]. The duality of digital innovation, with regard to its technology (i.e., the solution in development) and the individual dimension of market actors (i.e., the needs and potential use the technology is created for), has been considerably ignored in the innovation management literature [13]. Studies covering the individual dimension have stressed the existence of multiple heterogeneous innovation actors-socalled innovation collectives-where different actors share mutual goals and have similar skillsets, knowledge types, and behaviors [15]. The actors involved in innovation collectives include suppliers and potential customers, research centers and universities, cultural and social operators, policy-makers and institutions, entrepreneurs and start-ups, large companies, professionals and experts, and investors [16].

The emergence of innovation collectives is the outcome of specific attributes of digital innovation, such as convergence and generativity [3]. Therefore, scholars have dealt with it as an aftermath in relevant research. For example, Lubik and Garnesy [17] have asserted that the value creation process is dispersed and comprises value co-creation from various actors, who can potentially increase the generated value. Pellinen et al. [18] have highlighted that the innovation process can be influenced by the expectations and behaviors of different actors, following a co-evolutional pattern. Moro-Visconti [19] has revealed, using social network theory, that digital technology acts as an intermediary bridge, intensifying the interactions between various actors and improving communication quality; however, the author focused on the role and advantages of technology, rather than examining the social part of the digital socio-technical equation. Guo, Zhu, and Chen [11] have proved, using affordance theory in a single case study, that the digital platform drives and directs customer participation, enhances the experience of customers, and enables value co-creation through informational, actionable, or attitudinal behaviors. Yoo et al. [3] have emphasized, in their layered modular architecture, that innovation agencies engage heterogeneous actors to design and develop novel elements on external layers of their digital innovation platform. Further, the boundaries of those agencies have been loosened, in order to allow for interpretive flexibility between different actors, facilitate collaboration between various agents, and enable actors to organize their collaborative innovation [15].

Polykarpou and Barrett [20] are among the few scholars who have indicated a shift in the personal identity of actors in the process of digital innovation. The authors revealed that the potential of process and data sharing among various actors, enabled by digital tools, alters the traditional rules and norms of ownership, and leads to new arrangements of roles and relationships among various innovation actors. Huang et al. [21] and Ciriello 
and Richter [22] have described the role of innovation agents, in the digital context, as reflective agents who can situate themselves in the context of rapid scaling. Liu et al. [23] have revealed that the role of market actors, in the digital innovation process, comprises a major shift from traditional innovation management approaches (i.e., from "design for" to "design with"). Svahn et al. [10] emphasized that digital technology renews and improves the experience of market actors, thus creating new revenue streams and boosting sustainability.

Taken together, the literature covering the individual level has emphasized that digitally enabled innovation has radically transformed in its practice. This transformation is triggered by an open environment of flexible affordances, which encourages the heterogeneity of actors [4]. Yet, on the other hand, some scholars in the innovation field have proposed the opposite, stressing the need for homogeneous actors contributing to innovation development [2]. This area of inconsistency calls for the further need to focus on investigating the phenomenon of innovation collectives [4], as well as to provide additional knowledge on the roles of various actors in the digital context.

\section{Theoretical Background}

To address our research questions, we adopted value co-creation as a theoretical lens. Value co-creation theory has gone through three developmental stages: "value creation centered on product-oriented logic, value creation centered on service-oriented logic, and value creation centered on customer-oriented logic" [11] (p. 4). In value co-creation from customer-oriented logic, the current research stream has mainly addressed information sharing, co-operative behavior, and market actor engagement in innovation development. With respect to the engagement of market actors, the available research is insufficient and focuses on sub-dividing certain actions of value co-creation. Little research has been carried out on how value co-creation from market actor-oriented logic is digitally enabled, despite the existence of many studies acknowledging that innovation agents can achieve value co-creation through digital empowerment [11].

In terms of market actor-oriented logic, value co-creation theory has indicated that innovation agents and market actors can create value through interaction, where market actors are no longer at the opposite end of the innovation process. Instead, market offerings and requested benefits are generated through the involvement of market actors. Hence, the way in which value is created, exploited, and distributed is radically different from the traditional demand vs. supply model. Market-actor involvement in the process of value creation at various stages of the innovation process is viewed as engagement, which leads to empowerment and experience sharing, with a main emphasis on collectives and communities [24].

From a digital innovation-management perspective, the interaction between innovation agents and market actors is mediated by digital tools and platforms, leading to market-actor participation, innovation, and better market offerings. From the perspective of market actors, this occurs if they are adequately engaged and their expectations are met, in terms of their participation, empowerment, and involvement [24].

To conduct a balanced examination of digital innovation, in terms of actors, process, and technology, using value co-creation theory, we consider the need-solution coupling concept of von Hippel and von Krogh [9]. Need-solution coupling supports the idea of innovation collectives and is best-situated in the digital-innovation context, where the market dimension is as explicit as the technological dimension [9,13]. This practical approach, which was proposed by von Hippel and von Krogh [9], revolves around resolving the unnecessarily delimiting company-centric innovation that blocks innovation agents from crucial opportunities that can be captured by connecting the innovation process to its surrounding environment. Thus, it was found to be a suitable conceptualization to address the objectives of this study.

The need-solution coupling framework enforces a deep-rooted emergent notion of digital innovation, in which the interplay among the market and technological dimensions 
of innovation is loose-bounded, open-ended, and formed by the multi-level contextual behaviors and properties of different actors $[10,17]$. The framework describes the digital innovation process as a coupling process between the needs of actors and available technological solutions, at the initiation, development, and commercialization stages. In the process, different actors are expected to play different roles along the innovation cycle. This process is expected to be in a form of dynamic interaction between innovation process, innovation agencies, and market actors. Hence, the digital innovation process of innovation collectives is assumed to be an open process, and heterogenous actors are expected to be involved in the initiation, development, and commercialization activities [8]; see Figure 1.

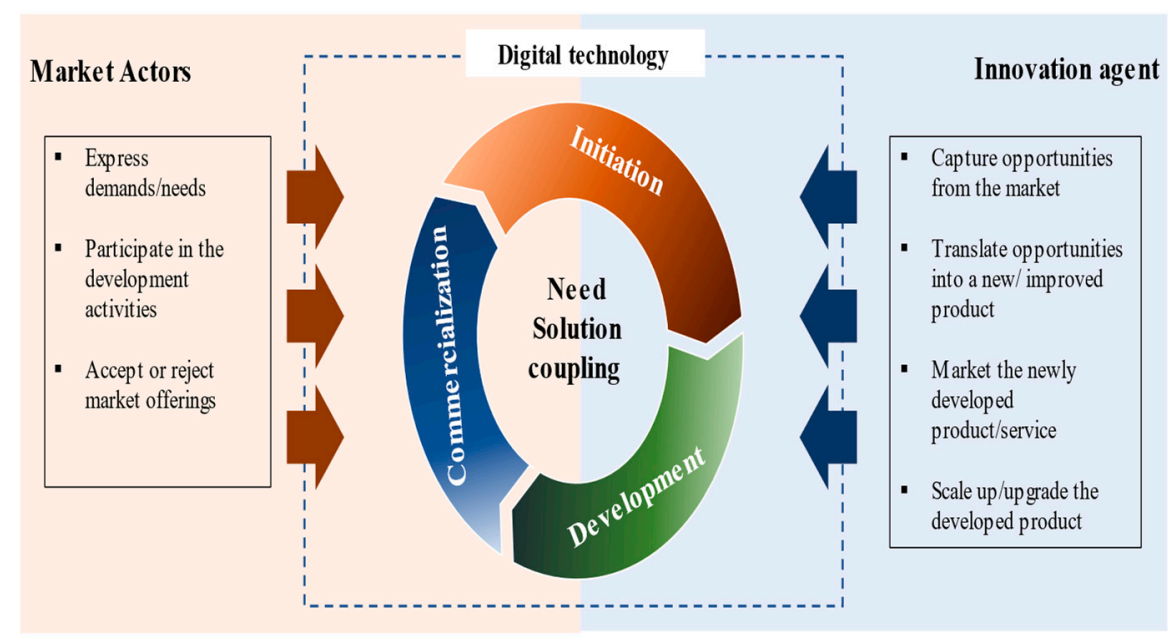

Figure 1. The individual dimension, from the need-solution coupling perspective.

To conduct a detailed examination of the individual dimension, we analyzed digital innovation at a process level, by systemizing the use of the need-solution coupling notion of von Hippel and von Krogh [9], in order to link innovation activities with the actions, behaviors, and needs of key actors [23,25].

By introducing the notion of need-solution coupling, we highlight that digital innovation indicates the continuous matching of digital technologies with existing market offerings. Hence, digital innovation can be viewed as a process of coupling and/or decoupling between the needs of market actors, digital tools and platforms, and the associated sociotechnical context [13]. The conceptualization of digital innovation as a dynamic needsolution coupling process indicates that the innovation space has fluid boundaries, which reflects the flexibility and openness offered by digitally enabled processes. Thus, this notion helps to address a key question: How do innovation agents integrate various diverse actors to contribute to digital innovation? [13].

The study analyzes the digital innovation process from the perspective of innovation collectives, and considers the emergence of need-solution couplings to be associated with the actions of individual actors, as well as those of innovation collectives, at the process level. At the collective level, the process is seen as a mutual platform which is enabled, by digital technology, to connect actors and their attempts for need-solution coupling. The interaction between actors in the process is induced by the objectives of actors, in order to utilize the innovation and its process as a solution to fulfil their needs $[5,9,23,25]$. The following section discusses the methodology of this study.

\section{Methodology}

Research methods are generally divided into quantitative and qualitative methods. Quantitative research defines, isolates, and categorizes variables. These variables are, then, linked, to create hypotheses that are to be tested upon data collection. Hence, variables are the means of analysis in quantitative research. On the other hand, qualitative research begins by defining general concepts that can change, in terms of definition, as the research 
progresses. Hence, variables can constitute the outcome of qualitative research. In short, qualitative research looks for patterns of relationships among a formerly unspecified group of concepts, while quantitative research looks at a determined set of variables [26].

This study uses a qualitative approach, for several reasons. The novelty of the topic calls for exploratory and descriptive approaches. Using a qualitative method in this research helped to understand the contextual meanings and related logics that help in understanding the innovation process and the roles of different actors under the influence of digital technology, as has been suggested by Nambisan et al. [13]. It also helps to examine the detailed process is carried out, and how digital technology affects it. In addition, the lack of research on the individual dimension of the digital innovation process, as well as evidence of the shift in personal identities of engaged actors, motivated us to explore the topic through use of a qualitative phenomenological approach.

Phenomenological research is inductive and descriptive. The researcher aims to understand the cognitive subjective perspective of the person who has the experience, as well as the effect that the perspective has on their lived experience [27]. As Merleau-Ponty [28] stated, 'We can only really understand phenomenology by doing it'. Patton [29] has defined a phenomenological focus as what people experience and how it is experienced. The methodological implications of studies that focus on lived experience is an individual's interpretation of the experience, which has been argued to be an essential part of the experience itself. Thus, based on our research questions, we adapted an interpretive phenomenological approach to develop an understanding of the digital innovation phenomenon, as Clark [30] has suggested that qualitative research is crucial in providing a rich context, prior to the application of any quantitative method.

To phenomenologically address the research questions, interview guides were designed, with semi-structured interview questions related to the research questions and the relevant literature. The interview questions fell into the following sections: the company's overall situation; the use of digital technology and its impact on innovation process; actor's contributions to innovation process; and how each actor contributes and at what stage. To validate the interview guide, we consulted several industry experts. Based on their recommendations, the interview questions were revised.

The study population consisted of SMEs operating in the Malaysian ICT sector. SMEs were selected, as $98.5 \%$ of companies in Malaysia are SMEs, which form $37.1 \%$ of the country's GDP [31]. Malaysian SME Masterplan 2012-2020 has established some policies to encourage innovation-driven SME growth and promote the adoption of digital technology. The priority of the Masterplan is to encourage business-service and production-process automation, as well as to emphasize the need for digital technology utilization [32]. One of the ways to boost innovation productivity in SMEs involves searching the market for potential opportunities to apply when modifying existing products. Accordingly, in order for Malaysian SMEs to survive, greater consideration has been paid to the innovation of new or modified products [33]. Therefore, in the Malaysian market scenario, innovation has been proven to be a significant strategy for the survival and growth of SMEs, which made them a suitable population for the purposes of this study. The characteristics of the Malaysian SMEs considered are presented in Appendix A.

The ICT sector was selected as it consists of knowledge-intensive companies that play a vital role in the economy, making them key sources, enablers, and users of digital innovation [31]. A considerable number of Malaysian SMEs operate in the ICT sector, contributing $18.5 \%$ to the Malaysian GDP. Furthermore, digital products/solutions from ICT companies are key enablers for the digitalization of other economic sectors [31]. Yet, studies on digital innovation in SMEs and the ICT sector are scarce [34]. The lack of resources in the literature in this field, among SMEs in general, and the ICT sector in particular, makes it hard to identify and adopt suitable management methods, and compromises the success of innovation processes within SMEs [35]. Hence, studying this sector of SMEs helps to cover some contextual gaps. 
Upon data collection, companies were purposefully selected, based on a set of clear criteria (see Appendix B). Our choice to use purposive sampling stemmed from our research objectives, wherein we had a set of topics that needed to be investigated and required a certain type of informant to obtain rich data. A purposive sampling technique assumes that the knowledge of a researcher about the population can be utilized to choose the sample based on specific criteria [36]. The core idea of purposive sampling is to choose participants with specific characteristics, who will better be able to assist with the relevant research. The strength of purposive sampling lies in its intentional bias in selecting participants, who can provide reliable and robust data [37].

The sample for this study was drawn from the Malaysian SME Corp's website [31], which provides a list of SMEs operating in various industries, located in different cities and states. The list for the ICT sector was retrieved in October 2018. On the date of access, the list consisted of 1385 companies, which represents the research population. Targeted respondents were either the top managers or the founders/owners of the SMEs. These respondents were considered as key knowledgeable informants and reliable source of information, in terms of different aspects of their companies [38,39].

Based on the set of pre-determined criteria, more than 800 companies were scanned. Companies without an official website were immediately discarded. The websites of selected companies were examined, in order to better understand the nature of products/services that they provided and the kind of digital technology that they utilized. Companies that did not demonstrate the use of digital technology or which did not have innovative commercialized products/services were discarded. Around 250 companies were found to be suitable, and were approached for interviews. Companies were contacted by email and phone, and companies who accepted the invitation were scheduled for a face-to-face interview at their convenience.

One of the most important aspects of a qualitative researcher is to determine the proper sample size. While qualitative methodologists tend to disagree on the needed sample size, they generally settle on factors that affect the size needed to reach data saturation. Some of these factors include the scope and nature of the research, the quality of interviews, and the sampling procedures, indicating a sample size ranging from six to thirty interviews [29]. One of the methods to determine an appropriate sample size is the statistical demonstration of data saturation. Data saturation "entails bringing new participants continually into the study until the data set is complete, as indicated by data replication or redundancy. In other words, saturation is reached when the researcher gathers data to the point of diminishing returns, when nothing new is being added" [40]. As a result, estimating an appropriate sample size is directly linked to the saturation concept. In this study, our primary goal was to conduct 10 to 20 interviews. Yet, data collection continued until it reached a point of saturation, which was confirmed on the 21st conducted interview.

All interviews were planned for the duration of one-to-three hours, with audio recorded and fully interpreted. The interviews and the follow-up process continued for a period of eight months, from November 2018 until June 2019. The characteristics of interviewed companies are presented in Appendix C.

\section{Data Analysis}

Data was analyzed within a process of integrating a descriptive analysis of the interviewed companies, the ICT industry, and a thematic analysis of transcribed texts, using the thematic analysis approach of Braun and Clarke [41] (see Appendix D). The NVivo 12 software was used to thematically analyze data. Peer-review coding by researchers was conducted, in order to avoid the disadvantages of pre-determined coding, improve the accuracy, and eliminate any bias. Next, reflection on the instances of disagreement took place, where we revised the analysis to exclude any variable that appeared to be based on personal interpretations, instead of the transcribed text. See Appendix E for themes coding.

Data was interpreted based on the two interpretation approaches: empathy and suspicion. Based on Ricoeur [42], "hermeneutics of empathy" means conducting interpretation 
based on the bottom-up approach, in order to get as close as possible to the text's potential meaning; while "hermeneutics of suspicion" is a top-down interpretation that depends on a "suspicious" attitude and intends to unveil a deeper meaning from the surface text. The author has argued that these interpretation types reveal various kinds of meaning and build various types of insights. Although Ricoeur [42] has effectively differentiated between the two interpretation types, he did not encourage the use of one over the other. The development of a new understanding requires an interplay among empathy and suspicion interpretations. However, qualitative methods differ in their degree of commitment to one of the interpretation approaches. For instance, descriptive phenomenology tends to rely more on hermeneutics of empathy, while interpretative phenomenological approaches rely more on hermeneutics of suspicion. However, both methodologies caution against interpreting data through pre-established theoretical frameworks, and both are committed to entering the phenomenon that presents itself, in order to understand its meaning and significance from within [43].

The current study aims to study and understand a phenomenon. It is necessarily based on specific research questions and is embraced by theory. To be able to address the research questions, it is important to interpret data based on the two approaches mentioned above: empathy and suspicion. Empathetic interpretation is used, in this study, to describe the roles of main actors during different stages of the digital innovation process, through the obtained data. On the other hand, suspicious interpretation is used to unveil deeper meanings from the surface text. Moreover, we followed the steps of the procedure given by Eisenhardt [44], in order to achieve trustworthiness; that is, validity and reliability. Validity indicates how realistic the findings are, whilst reliability refers to the degree of replicability of the study.

\section{Results}

Based on the need-solution coupling notion of von Hippel E von Krogh [9], the individual dimension was analyzed at three main stages of the digital innovation process: Initiation, development, and commercialization. Appendix F provides exemplary quotations.

\subsection{Initiation Stage: Shift in Roles of Innovation Agents and Market Actors}

Data analysis indicated that, at the initiation stage, innovation agents act based on the desires and demands of market actors. The respondents explained that innovation is initiated by identifying and analyzing the needs of market actors that can be served by the set of solutions available to innovation agents. For instance, Company $\mathrm{G}$ views themselves as a 'tailor house,' driving innovation directly in response to the requests of market actors, demonstrating their responsive role and the authoritative role of market actors.

Innovation agents identify the needs of market actors directly, through listening to their demands (i.e., explicit needs), and indirectly, by sensing market gaps or "pain points" (i.e., implicit needs). In the responsive approach, market actors clearly state their issues or demands, and innovation agents initiate the innovation cycle by responding to these demands. Those explicit needs are mainly collected through digital platforms, which are designed for this purpose. For example, company N created a platform called "talk to $\mathrm{CEO}$," where market actors can directly provide their input to the company's CEO. In the proactive approach, innovation agents approach the market to sense and capture market gaps or the needs of actors, and predict ways to fill those gaps. Respondents rely largely on big data to sense and capture implicit needs. Big data helps innovation agents to accurately predict and analyze implicit market needs. Companies $G$ and F clarified that big data supports the generation of innovative ideas and improves their ability to realize market trends and innovate, accordingly.

After recognizing the needs of market actors, innovation agents utilize digital technology to respond to those needs. The respondents emphasized that innovation should not only be based on technology. Instead, it should be the result of integrating technological solutions with market needs, giving favor to the later. As such, technology serves as a 
supportive tool to respond to the market, by providing solutions that can fulfil the needs or demands of market actors.

In addition, the respondents elucidated that the initiation stage entails validation procedures for market needs and technological solutions, including evaluating the detected need, the potential solution, and the ability of the potential solution to satisfy the needs of market actors. Innovation agents conduct this validation step to estimate the market success of the potential innovative solution, ensure that the potential solution can satisfy the intended need, and to prove that the solution is implementable, applicable, and costeffective. Market actors are engaged in this validation procedure as decision makers, while innovation agents act as responders who capture external knowledge (i.e., the needs of market actors), and integrate this knowledge with internal knowledge (i.e., potential solutions) to generate a viable output (i.e., technological solutions responding to market needs). Thus, in the initiation stage, companies play a reflective role, while customers play an authoritative role.

- The participants indicated that giving control to market actors, as drivers of innovation, is important to increase the potentiality of market acceptance upon product launch. Several participants emphasized that innovative ideas that are not initiated by market actors inherently have high uncertainty and risk. Company B shared that they had developed a digital product which was based on their own generated ideas, and did not project the idea against the needs of market actors, or evaluate it based on market acceptance. As a result, the product failed in the market. Company $\mathrm{K}$ also shared a similar experience of failure. Subsequently, companies $\mathrm{H}, \mathrm{K}, \mathrm{B}$, and J explained that, based on their experience, avoid the internal generation of innovation ideas and relies on market to initiate innovation.

\subsection{Development Stage: Innovation Co-Creation}

In the development stage, innovation agents engage market actors in prototyping and testing the initial design of a product, exchange ideas, and finalize its design and features. Respondents stressed the necessity of prototyping to make concepts and ideas tangible to users. Thus, ideas become simpler to understand, in order to discuss potentials and to challenge alternatives with market actors. They also expressed the significance of engaging market actors in prototyping, in order to ensure the implementability of the potential product and its alignment with market requirements and expectations. In addition to prototyping, several respondents captured the feedback and enquiries of market actors, through surveys, discussion sessions, and meetings. Such enquiries can help to improve the features of potential innovative products, evaluate product market attractiveness, and estimate the risk of market rejection.

Innovation agents closely collaborate with their target market actors by utilizing digitally enabled communication tools. Digital communication tools enable the customer to be heard, which improves collaborations to identify the desired attributes and features for future product designs. According to company M, digital communication tools (e.g., social media and apps) enabled them to save operation costs by eliminating physical barriers, improving communication and coordination across projects team members, and support efficient and effective distance operations.

After design testing, innovation agents translate ideas into a tangible innovative product, relying mainly on the requirements and preferences of market actors. The respondents emphasized their policy of engaging market actors at every step of the development stage. Market actors follow each milestone, and their inputs are considered before, during, and after product/service design and development. Company G, for instance, described the need to obtain consent from market actors at different points of product development, by exchanging knowledge with them and measuring their satisfaction with project progress. Thus, market actors acquire a co-creational role, in this stage, whilst innovation agents play a responsive role. 


\subsection{Commercialization Stage: Market Actor Testing and Initiating Roles}

Once the service or product is developed, commercialization activities occur, in terms of closing the deal, testing and launching the product, feedback and knowledge sharing, support and maintenance, and product upgrading. Market actors are engaged in different essential activities at this stage; for instance, they test the product, in terms of functionality and mass usage; receive training sessions to learn about the new product usage and value; receive after-service maintenance and support; and provide feedback on user acceptance and the user experience.

The respondents explained the additional roles that market actors undertake in this stage, including suggestions for service improvement, complaints, compliments, and appraisals toward the service and its providers. For instance, company $\mathrm{N}$ shared that acquiring market-actor input at this stage provides customers with more control over the products/services of innovation agents, enabling them to sustain the success of their products/services.

Innovation agents utilize digital tools, in this stage, to conduct online marketing and initiate product sequencing activities. By utilizing online marketing techniques, innovation agents can expand their market through space, in order to reach overseas markets without the need for vast marketing investments. The respondents claimed that online marketing can provide efficient tools to attract and maintain market actors, such as search engines, company websites, online advertising, and social networks. It also provides efficient tools to attract and maintain customers. Hence, the efficiency of online marketing stems from its ability to reach the needed market segment with fewer resources. On the other hand, respondents employ social media through use of sentiment analysis, in order to document positive/negative responses to the launched product; to identify areas for improvement; and to make data-driven decisions based on the opinions of market actors, in terms of the attractiveness and applicability of the launched product, which leads to the initiation of product sequencing activities.

Market actors take part in marketing activities as well. Innovation agents rely on the peer-recommendations of market actors who took part in the initiation and development stages to market their products/services, through networks and connections. Based on the responses of companies, networking is considered a low-cost marketing strategy. Company F stated that networking is necessary to succeed in the market; while company D viewed networking as a cultural attribute, and elaborated that it is an embedded perspective in the Malaysian culture and a necessary marketing tool in the Malaysian market. Company $Q$ explained that success is all about building a trusting relationship with market actors. This trust is generated by engaging them in the innovation process, and can attract new users while sustaining their relationship with existing ones. Market actors that are attained through networking activities were also found to be essential contributors to business success. Based on company $\mathrm{F}$, the influence of market actor engagement in the innovation process can be considered a branding tool that leads to positive word-of-mouth.

The main result of market-actor engagement in the commercialization stage activities is product sequencing, which leads to product improvement, product evolution, and the initiation of new innovative ideas. These sequencing activities lead to a continuous cycle of development and improvement. For example, Company $\mathrm{N}$ elaborated on how their products evolved over time, due to market actor engagement in the development stage, while Company B was inspired to develop another product, based on market actor inputs on one of their launched products.

In summary, market actors are extensively engaged in all stages of digital innovation development (see Figure 2). The respondents expressed numerous positive outcomes from engaging market actors, as key enablers and drivers of innovation activities, such as improving the understanding of user needs and reducing development costs, increasing internal knowledge, enhancing service/product design, lifting the potential for success and sustainability, and reducing the risk of failure and market rejection. 


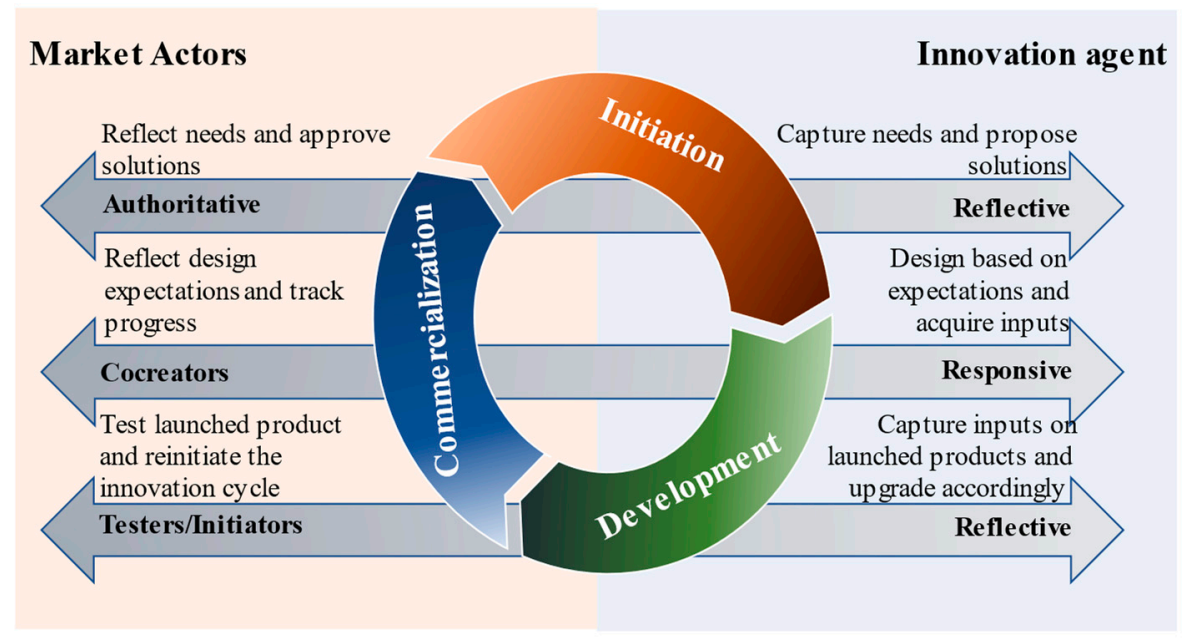

Figure 2. The shifted roles of market actors and innovation agents.

The respondents clarified that innovation agents can still operate without employing digital technologies; however, such technologies create new areas for innovation. Being dedicated to technological trends and adopting suitable digital tools enable innovation agents to develop solutions that correspond to current market trends, which helps them to achieve sustainability. Such sustainability is achieved by:

1. Enabling cost reduction and speed operations, through the automation of different operational activities.

2. Allowing a heterogenous pool of actors to be actively engaged in the innovation process, which enables innovation agents to tap into a larger pool of knowledge and, thus, improves the efficiency and effectiveness of their innovative activities.

3. Increasing the efficiency of communication and distribution channels, allowing for a large amount of data to be quickly circulated between various actors.

4. Improving the dynamism and transparency of the innovation processes, by eliminating intermediaries and directly linking innovation agents with market actors. This transparency builds trust, which is required to increase the satisfaction and purchasing desire of market actors.

5. Gathering a huge mass of data, as business intelligence, can be used to predict market trends, plan and make decisions, modify existing products, improve user experiences, and to serve market actors and attract new ones.

\section{Discussion}

This study was conducted to investigate the roles of key actors during the development of digital innovation, through the use of value co-creation theory. Interviews were carried out among industry players involved in digital innovation processes. Our findings contribute to the under-studied area of the individual dimension of digital innovation, by investigating the roles of main actors during its process, through a stage-level analysis. We revealed that digital innovation projects revolve around the needs and expectations of market actors. The results articulated that digital technology enables and facilitates the engagement of market actors under a need-solution coupling approach. Need-solution coupling refers to the ability of innovation agents to create value through recognizing, validating, and responding to the needs of market actors. To follow this approach, innovation agents merge the digital innovation process with its surrounding environment (e.g., market), and act as responsive agents. In contrast, market actors play an authoritative role, by identifying, accepting, or redirecting the proposed solutions with respect to their declared/recognized needs. Our results confirm that need-solution coupling can successfully explain how digital innovation emerges and evolves [13,45], as well as shedding light on the individual dimension of this coupling. 
Our findings indicate the significance of engaging market actors, in order to reduce the uncertainty and risk of digital innovation projects. The respondents emphasized that progress from the initiation stage to market launch is accompanied by the extensive engagement of market actors and by continuous knowledge circulation between innovation agents and their target markets. Such knowledge restrains losses, through the detection of flaws and errors, both early on and before market launch. Several scholars have articulated that having a market-centric orientation can improve the potential success of an innovation [46-49]. However, the findings of this study explain how this market orientation is carried out in a digital innovation context, through an alteration of the roles of main actors; where, at some points, control and authority are shifted to market actors. Furthermore, our findings extend the knowledge regarding such role alteration, by revealing the role that market actors play at each stage of the digital innovation process and the amount of control that they exert on the innovation direction and endeavors.

The original findings of this study relate to where and when in the innovation process market actors become engaged and the role that they play at each stage. For instance, market actors play an authoritative role at the initiation stage, where their inputs serve to make the 'go' or 'kill' decision. When market actors reject a potential solution, the innovation agent will tend to discard the solution and present another one. These findings contradict previous studies in the literature, who viewed market actors as mere data sources that innovation agents control and utilize [25,50]. Guo et al. [11], in their single case study, revealed the significance of market actors and explained that aligning innovation with the needs of market actors stimulates their interest and encourages them to become engaged in value co-creation behaviors. In other words, need-solution alignment is a pre-requisite for market actors to become active contributors to the innovation process. The findings of Guo et al. [11] are in alignment with the findings of this study, and explain why market actors are willing to engage in the innovation process.

At the development stage, market actors play a co-creational role, and participate in identifying or approving the potential design features of a new product. Some scholars have stated that engaging market actors in the development stage can slow down innovation and negatively influence its endeavors [51], while other scholars, such as Polykarpou and Barret [20], have indicated that shifts in the roles of actors during the co-creation process can create collaboration challenges. However, the findings of this research are in line with those of several scholars, who have indicated the importance of engaging market actors at this stage, in order to enhance product features and innovation sustainability $[50,52]$. At the commercialization stage, market actors test the launched product to determine initial satisfaction and share any product functionality concerns. Hence, customers play a tester role at this stage. At this stage, market actors are also engaged as initiators and inspirational agents, as they can propose new ideas or reflect new needs to improve and scale up the launched product. Market actors can also act as marketers and salesmen themselves, supporting the distribution of the launched product(s). Such findings can also be seen in the case study of Guo et al. [11], who revealed the willingness of market actors to distribute innovation agents' product(s) via network marketing. Meanwhile, the role of innovation agents has shifted from being innovation initiators to cogitative actors, by receiving and absorbing knowledge from market actors into the digital innovation process. These outcomes confirm the conceptual premises proposed by Nambisan et al. [5]: that digitally enabled innovation openness modifies the degree and nature of who can participate, what they can contribute, how they can contribute, and to what ends.

It has been widely recognized that digital technology can facilitate the participation of heterogenous actors through innovation co-creation activities. For instance, Guo et al. [11] explained that market actors are attracted to products that are aligned to their needs, yet their ability to engage and participate in the innovation process is related to the existence of an enabling digital platform that forms a channel of openness and communication. This digital platform helps to create the required trust between innovation agents and market actors, in order for both to be successfully engaged in value co-creation activities. 
However, the mechanisms by which technology enables and facilitates this engagement at different stages of the innovation process is not well-understood [11]. The results of the current study contribute to the knowledge of 'how' digital tools enable and facilitate these alterations in the roles of actors.

Findings indicates that innovation agents go beyond the simple automation of existing processes, to the utilization of digital technologies to improve their ability to capture and create value, by facilitating the engagement of market actors as active key players. Different digital tools are used at different stages and for various purposes. Innovation agents pointed to the use of big data and analytical tools in the initiation and commercialization stages, in order to drive decision making, analyze the market, and reduce the costs of resources. At the initiation stage, digital platforms are also used to get in direct contact with market actors, in order to identify their needs and expectations. At the development stage, innovation agents use communication and coordination tools to speed up and improve the efficiency of co-creation activities. At the commercialization stage, marketing and communication tools facilitate distribution and re-initiate the innovation cycle.

Our findings indicated that digital technology boosts innovation sustainability, as it provides the necessary tools to change the methods of value creation, increases innovation efficiency, reduce operational costs, and speeds up the innovation process. It also allows for transparency, which can create trust between innovation agents and market actors, provides a platform for ease of communication and participation, creates a context of co-creational activities, and provides distribution channels that can attract further participation and adoption. In line with these findings, Moro-Visconti [40] indicated that digital platforms act as intermediating hubs that reshape the interactions between engaged actors and improve data diffusion, which can benefit all engaged actors, in terms of achieving business sustainability. Roukouni et al. [41] have emphasized that the digital engagement of market actors in innovation development can improve sustainability through increasing the flow of knowledge, facilitating innovation adoption, and relieving trust and uncertainty issues. Del Vecchio et al. [42] found that using communication and marketing tools at the commercialization stage can contribute to a better understanding of the needs of market actors and generate trust and involvement, thus helping to create a sustainable consumption culture. In contrast, Heim et al. [53] and Kawakami et al. [54] had concerns about digitally engaging market actors in the initiation stage of the innovation process, in terms of the fear of innovation agents regarding losing control over the process direction. These concerns contradict the current study, which demonstrated the long-term advantages of losing authority to market actors at the initiation stage. Generally, it can be concluded, from the findings of the current study, that digital technology support innovation by serving as a force that drives companies to innovate, as a compass to direct them where to innovate, and as a tool to facilitate their innovation activities.

In conclusion, this study reinforces the importance of engaging market actors initially and during the digital innovation process, in order to achieve success and sustainability. Thus, digital innovation can be seen as a process of value co-creation, which emerges as various heterogenous actors interact and exchange knowledge through digitally-enabled platforms. It was revealed that the digital technology reshapes the innovation process, loosens the boundaries of innovation agencies, and shifts authorities and control to market actors. The importance of market-actor engagement has been stressed in many scholarly works; which, along with the findings of this study, indicates that the innovation process has been altered in the digital context. Overall, this calls for a radical change in the way that the literature perceives innovation.

\section{Contributions, Implications and Limitations}

Most studies have viewed digital innovation from technical, architectural, or information system perspectives, but not from an individual perspective [43]. The lack of specific insights regarding the individual dimension of digital innovation has led to calls for further and more detailed analyses $[4,44]$. Considering that digital innovation is still nascent and 
currently in a growth spurt, examining key developments in the field will help to systemize the current knowledge and uncover fruitful avenues for future research [4]. Thus, in this study, we utilized the need-solution coupling approach to investigate the individual dimension of digital innovation in a process-level analysis. The current study contributes to the value co-creation theory, by adopting it from customer-oriented logic, which remains understudied and requires further assessment [11]. Our findings extend the state of knowledge on the interactions between technology and actors in the value co-creation process. We interpreted and extended the analysis of the market dimension, from the narrow view of user knowledge and customer information to cover the needs, behaviors, and actions of various actors who (directly or indirectly) use, complement, or substitute the innovation and its process. Our results indicated the altered role of innovation agencies and explained the roles of market actors during different activities of the digital innovation process. This study also contributes by allowing for a better understanding of how digital technology enables the alteration of such roles.

This research specifically attempted to provide a better understanding of innovation processes in the digital context. Our findings provided managerial implications, regarding the way in which innovation agents can enable the engagement of market actors in value co-creation. This study contributes to a better managerial understanding of how role alteration can be rewarding for innovation agents, as well as market actors, improving the potential of innovation success and reducing its uncertainty and risk for innovation agents, whilst attracting market actors and improving their satisfaction. It also helps to increase the awareness of innovation agents, in terms of the advantages of digital tools in improving their competitive advantage and boosting sustainability. From the power and authority perspective, we showed that handing control to market actors, at some points during the innovation process, can be of great benefit for the associated innovation outcomes. In addition, we revealed — to a certain extent-the internal secrets of how digital technology enables value co-creation and provides a platform to support companies to innovate, based on value co-creation. Overall, this study revealed managerial implications on how digital tools and platforms can promote innovation, by enhancing the engagement of market actors and provide insights on the methods and mechanisms of value co-creation. The outcomes of this research can play a role in shaping future practices, increase manager awareness, extend their understanding of the individual dimension of digital innovation, and encourage the utilization of digital platforms and tools, in order to frame their innovation processes in a way that improves market-actor engagement.

The study scope imposed some limitations, which open avenues for further research. This research was qualitative by nature, limiting its ability to generalize the findings; however, the results may serve as a basis for future research. More qualitative and quantitative studies need to be carried out in other sectors in Malaysia, in order to test and compare the results of this study. There is also room to compare the Malaysian ICT sector with ICT sectors in other countries, to better understand the associated differences and similarities. Moreover, the conclusions of this study were limited by the use of data from only twenty-one companies. Further qualitative and quantitative research is needed, in order to validate, confirm, or reject the presented findings. Further research needs to be conducted to examine how the current findings apply to traditional manufacturing industry, to compare the differences and similarities between manufacturing and service industries. In addition, this study was conducted from the perspective of innovation agents; further studies are required, in order to address the perception of market actors, regarding the innovation process, and how they influence or are influenced by it. Finally, this study advances the understanding on digitally enabled innovation processes from the perspective of managers who intend to do it successfully. Yet, we limited the assessment to two key actors: innovation agents and market actors. Therefore, further studies considering the perspectives of other actors, such as suppliers and governmental bodies, are required.

Author Contributions: Conceptualization, H.A.; methodology, H.A.; validation, H.A.; formal analysis, H.A.; investigation, H.A. and S.M.; data curation, H.A.; writing-original draft preparation, 
H.A.; writing - review and editing, S.M.; supervision, S.M. All authors have read and agreed to the published version of the manuscript.

Funding: This research received no external funding.

Institutional Review Board Statement: The study was conducted according to the guidelines of the declaration of Helsinki, and approved by the UM Research Ethics Committee (UMREC) at the University of Malaya (protocol code UM.TNC2/UMREC-443 and date of approval February 2019).

Informed Consent Statement: Informed consent was obtained from all subjects involved in the study.

Data Availability Statement: The data presented in this study are available on request from the corresponding author. The data are not publicly available due to privacy reasons.

Acknowledgments: We would like to express our appreciation to Abdallah Allataifeh, Hamed Motaghi and Sorin Cohn-Sfetcu for their valuable and constructive suggestions during the planning and development of this research work.

Conflicts of Interest: The authors declare no conflict of interest.

\section{Appendix A}

Table A1. Definition of SMEs in Malaysia.

\begin{tabular}{|c|c|c|c|c|c|c|}
\hline \multirow[b]{2}{*}{ Size } & \multicolumn{2}{|c|}{ Micro } & \multicolumn{2}{|c|}{ Small } & \multicolumn{2}{|c|}{ Medium } \\
\hline & $\begin{array}{c}\text { Sales } \\
\text { Turnover }\end{array}$ & Employees & $\begin{array}{c}\text { Sales } \\
\text { Turnover }\end{array}$ & Employees & $\begin{array}{c}\text { Sales } \\
\text { Turnover }\end{array}$ & Employees \\
\hline manufacturing & 400 & & $\begin{array}{l}\text { RM 300,000 to } \\
<15 \text { million }\end{array}$ & $\begin{array}{c}5 \text { to }<75 \\
\text { employees }\end{array}$ & $\begin{array}{l}\text { RM } 15 \text { million } \\
\text { to } \leq 50 \text { million }\end{array}$ & $\begin{array}{l}75 \text { to } \leq 200 \\
\text { employees }\end{array}$ \\
\hline $\begin{array}{l}\text { service \& other } \\
\text { sectors }\end{array}$ & <NIVI 300,000 & - спіріоуеез & $\begin{array}{l}\text { RM 300,000 to } \\
<3 \text { million }\end{array}$ & $\begin{array}{c}5 \text { to }<30 \\
\text { employees }\end{array}$ & $\begin{array}{l}\text { RM } 3 \text { million to } \\
\leq 20 \text { million }\end{array}$ & $\begin{array}{l}30 \text { to } \leq 75 \\
\text { employees }\end{array}$ \\
\hline
\end{tabular}

\section{Appendix B}

Table A2. Criteria for Sample Selection.

\begin{tabular}{|c|c|}
\hline firm size & $\begin{array}{l}\text { Only SMEs will be selected. Large companies will be excluded from the study, as they do not } \\
\text { represent the population of Malaysian companies. }\end{array}$ \\
\hline ict sector & Companies will be selected from the ICT sector, as the research phenomenon is in the digital context. \\
\hline sme's location & $\begin{array}{l}\text { SMEs located in Klang Valley region are selected. These companies are located in Kuala Lumpur and } \\
\text { its neighboring suburbs, towns, and cities in the Selangor state. This area is recognized for its more } \\
\text { than } 23 \% \text { GDP of economic growth rate, which is being built by Kuala Lumpur and Selangor, } \\
\text { corresponding to the Department of Statistics Malaysia (DoSM) (2017). Furthermore, a substantial } \\
\text { proportion of SMEs involved in the services sector (which ICT is a part of) are present in Klang Valley } \\
\text { area, contributing to a competitive business market. }\end{array}$ \\
\hline innovative companies & $\begin{array}{l}\text { Innovative companies that introduce at least one identifiable commercialized innovation project, } \\
\text { which can create value for the company and its stakeholders. }\end{array}$ \\
\hline locally owned & Foreign-owned companies will be excluded from this study. \\
\hline accessible to researcher & $\begin{array}{l}\text { Interview research needs good transparency and collaboration (Yin, 2014). Thus, it is significant to } \\
\text { choose companies that express a high level of interest in engaging in the research and were available } \\
\text { at the time of conducting the study. }\end{array}$ \\
\hline information content & $\begin{array}{l}\text { The participant needs to give enough details about the phenomenon considered in the research to } \\
\text { allow the researcher to properly examine the research question. }\end{array}$ \\
\hline
\end{tabular}




\section{Appendix C}

Table A3. Characteristics of the selected sample.

\begin{tabular}{|c|c|c|c|}
\hline Company Name & Company Age & Company Services and Products & Participant's Position \\
\hline \multicolumn{4}{|c|}{ Middle-size companies } \\
\hline Company A & 23 years & $\begin{array}{c}\text { Big Data Analytics, Cloud Computing, and Software } \\
\text { Engineering }\end{array}$ & $\mathrm{COO}$ \\
\hline Company C & 14 years & $\begin{array}{l}\text { Information technology, internet of things, project } \\
\text { management services, security solutions and management, } \\
\text { desktop solutions and management, and networking }\end{array}$ & director \\
\hline Company K & 20 years & Artificial intelligence and internet of things & CEO \\
\hline Company M & 14 years & $\begin{array}{l}\text { Digital Project Management, Project Management Training } \\
\text { and Education, Business Process Improvements, Big Data, } \\
\text { and Business Intelligence }\end{array}$ & vice president \\
\hline Company F & 10 years & $\begin{array}{l}\text { IoT, business consultancy, e-marketing, and solution } \\
\text { development }\end{array}$ & owner and CEO \\
\hline Company Q & 9 years & $\begin{array}{l}\text { Efficient and Convenient Odoo ERP and CRM solutions for } \\
\text { enterprises, co-creation software product development } \\
\text { partnership, Mobile Applications, and Data Visualization }\end{array}$ & owner and CEO \\
\hline \multicolumn{4}{|c|}{ Small-size companies } \\
\hline Company D & 5 years & $\begin{array}{l}\text { Consulting, Technological and Digital HR Solutions, } \\
\text { Programme and Project Management }\end{array}$ & $\mathrm{CIO}$ \\
\hline Company B & 10 years & $\begin{array}{l}\text { Artificial intelligence, app development, and internet of } \\
\text { things }\end{array}$ & owner and MD \\
\hline Company G & 15 years & $\begin{array}{l}\text { IoT, mobile apps and website development, hosting services, } \\
\text { UI and UX design, digital marketing, and solution providers }\end{array}$ & owner and CEO \\
\hline Company J & 4 years & $\begin{array}{c}\text { Online Tools, NEM Merchandise Shop, Blockchain Crypto } \\
\text { Consultancy, Blockchain App Design, NEM Supernode } \\
\text { Service, Network, and Bitcoin Lightning }\end{array}$ & $\mathrm{CIO}$ \\
\hline Company I & 6 years & IT Services, IT Solutions Provider, and Supply Chain Services & owner and CEO \\
\hline Company E & 11 years & Consultancy, websites, and mobile app development & CEO \\
\hline Company L & 3 years & Blockchain development service, training, and consultancy & co-owner and CTO \\
\hline Company $\mathrm{O}$ & 19 years & $\begin{array}{l}\text { Data Centre and Enterprise Networking, and Surveillance } \\
\text { Solutions }\end{array}$ & owner and CEO \\
\hline Company P & 11 years & App development & owner and CEO \\
\hline Company $\mathrm{H}$ & 3 years & $\begin{array}{l}\text { Analytics consultancy and training, Applied Analytics, } \\
\text { Analytics Talent Upskilling (ATU), and Sentiment Analysis }\end{array}$ & owner and CEO \\
\hline Company $\mathrm{N}$ & 5 years & $\begin{array}{l}\text { Management consultancy and training, Product Discovery, } \\
\text { Web and Mobile Development, and Digital Transformation }\end{array}$ & owner and CEO \\
\hline Company R & 5 years & IoT, Cloud computing, and Artificial Intelligence & owner and CEO \\
\hline Company S & 5 years & $\begin{array}{l}\text { Specialized in connected fitness, wellness, and healthcare } \\
\text { technology solutions }\end{array}$ & founder \& CEO \\
\hline Company $\mathrm{T}$ & 5 years & $\begin{array}{c}\text { Contact center management, IT management, App and Web } \\
\text { development }\end{array}$ & $\mathrm{CEO}$ \\
\hline Company U & 4 years & Business end-to-end management and networking & founder \& CEO \\
\hline
\end{tabular}




\section{Appendix D}

Table A4. Braun and Clark Thematic analysis.

familiarization with data

initial coding

generating themes

reviewing themes

defining and naming themes

writing up
The aim of this step is to gather all potential occurrences that emerged from the text record of the interviewees. The researcher becomes familiar with the data by repetitively reading the text and reporting any initial analytical observations.

Coding is not a method of data reduction; instead, it is an analytic process. Codes should include a conceptual and semantic reading of the data. The researcher begins coding by interpreting the meaning of what had been said. The researcher starts coding with research questions and theory in mind. This involves highlighting significant features of the data that are related to the research questions guiding the analysis. The researcher codes every data item and ends this phase by comparing all codes and relevant data extracted.

A theme is a meaningful and coherent pattern of data that is linked to the research question. Searching for themes is similar to coding your codes to identify similarity in the data. The researcher constructs themes, and text that could not be categorized with the initial coding scheme is given a new code. The coded data is confirmed to be related to each theme to end this phase.

This stage implies checking that the themes 'work', in relevance to both the full data set and coded extracts. The researcher reflects on whether the themes tell a compelling and convincing story, regarding the data, and starts to determine the nature of each theme, as well as the relationships between the themes. Certain themes are split into two or more themes, others are collapsed together, while some themes are discarded.

This phase demands that the researcher writes and produces a detailed analysis of each individual theme. The researcher determines the 'essence' of each theme and provides an informative name and a brief description for each theme.

The writing stage is an integral part of the analytical process. The researcher describes the findings of the data analysis, by answering the research questions according to both existing and new codes

\section{Appendix E}

Table A5. Emergent Themes and codes.

\begin{tabular}{|c|c|c|c|c|c|c|c|c|c|c|c|c|c|c|c|c|c|c|c|c|c|c|}
\hline \multirow{2}{*}{$\begin{array}{l}\text { Categories of } \\
\text { Construct }\end{array}$} & \multirow{2}{*}{ Emergent Themes } & \multicolumn{21}{|c|}{ Companies } \\
\hline & & A & B & $\mathrm{C}$ & D & $\mathrm{E}$ & $\mathbf{F}$ & G & $\mathbf{H}$ & I & $\mathbf{J}$ & $\mathbf{K}$ & $\mathbf{L}$ & $\mathbf{M}$ & $\mathbf{N}$ & $\mathrm{OP}$ & $\mathbf{P C}$ & $\mathrm{QR}$ & R S & $S$ & $\mathrm{~T}$ & $\mathbf{U}$ \\
\hline \multicolumn{23}{|c|}{ Innovation agent roles } \\
\hline all stages & $\begin{array}{c}\text { reflective/responsive } \\
\text { agents }\end{array}$ & & $x$ & $x$ & $x$ & $x$ & $x$ & $x$ & $x$ & $x$ & & $x$ & $x$ & $x$ & $\mathrm{x}$ & & & $x$ & & $x$ & $\mathrm{x}$ & $x$ \\
\hline \multicolumn{23}{|c|}{ Market actor roles } \\
\hline initiation stage & authoritative role & $x$ & $x$ & $x$ & $x$ & $x$ & & $x$ & $x$ & & $x$ & & & $x$ & $x$ & $x$ & & $x \quad x$ & $x$ & & $x$ & $\mathrm{x}$ \\
\hline development stage & co-creator role & $x$ & & $\mathrm{x}$ & $x$ & $\mathrm{X}$ & & $x$ & $\mathrm{x}$ & & $x$ & & & $x$ & $x$ & & & $x \quad x$ & $x$ & & & \\
\hline \multirow{2}{*}{ commercialization stage } & tester role & $x$ & & $x$ & $\mathrm{x}$ & & & $\mathrm{x}$ & $\mathrm{x}$ & & & & & $\mathrm{x}$ & $x$ & & & $\mathrm{x}$ & & & & $\mathrm{x}$ \\
\hline & initiator role & & $x$ & $x$ & $x$ & & $x$ & $x$ & $x$ & $x$ & $\mathrm{x}$ & & $x$ & $x$ & $x$ & $x$ & & $x \quad x$ & $x \quad x$ & $x$ & $x$ & $\mathrm{X}$ \\
\hline
\end{tabular}




\section{Appendix F}

Table A6. Exemplary Quotations on Emergent Themes.

\begin{tabular}{|c|c|}
\hline $\begin{array}{l}\text { Main Emergent } \\
\text { Themes }\end{array}$ & Exemplary Quotations from Respondents \\
\hline $\begin{array}{l}\text { innovation agents as } \\
\text { reflective agents }\end{array}$ & $\begin{array}{l}\text { "we listen, understand and respond with innovative and creative solutions that adds value to the clients" } \\
\text { [company C]; "we always say that we are a tailor house: we have you to tailor whatever you feel like is } \\
\text { nice to wear for you. This is our role... we can only tell you based on your requirements, we will try the } \\
\text { best to do for you and the best will it be. That's our limit" [company G]. }\end{array}$ \\
\hline
\end{tabular}

"Usually, clients ask us to do that thing because they want it" [company G]; "So, from [listening to client] we understand what the client needs" [company M]; "So I got to put my salespeople, and they will go out to smell those opportunities" [company A]; "we found that emerging need in the market" [company H]. "You cannot have blockchain and then you look up for problems. So, if the problem exist, whether blockchain serves that is very important ... Whether AI resolve that is very important" [company Q]; "you need to be clear with what the problem is ... it depends on your problem whether the technology is the solution" [company D].

"do really customers need this? What is the pain point? Do you really see the pain? Do they really need it?" [company A]; "assess each of the solutions" [company C]; "if I want to implement a solution so we actually try to see whether it fit the needs" [company M].

someone comes with an idea; we need to evaluate whether it is doable or not" [company T]; "make sure that the market fit to the solution is very important... That comes to validations" [company Q]; "in doing all these evaluations, you can get to a point where you realize that: yes, we are capable of taking this

customer's authoritative role opportunity and do well" [Company T].

"validation is needed. I shared this idea, and I received the feedbacks to improve the idea before lunching it" [company H]; "the best way to do anything is to validate. Validation is an important process, which means before you design something you actually talk to the customers not directly about the product but about what is their experiences. Let's say for an example, when we are designing this medical product, we don't know whether it will be successful of not, there is a 50-50 chance. But we involve the real stakeholders, we involve the shares of the company, we involved the doctors. If the real stakeholders will talk about the product so this is will work" [company C].

"So, essentially the product and the customer should be able to have some "product-market fit" which is very important" [company Q]; "from there we understand what the client needs, and we try to cater that to what we want to deliver to them" [company M].

"you want to share the idea with small market for you to get the right feedback and go deep in the discussion. So, you check, you have some metrics to validate; did I validate this this and this; if not, I have to iterate; I have to come back, change the business model, change the pricing, change everything until I validate" [company U].

"when you build the product, build a prototyping model" [company Q]; "we conducted a lot of pilot studies" [company S]; "most of the time the issue will be that customers don't like the design ... because when they put in the requirement, they cannot see the system yet ... now we do [prototyping]" [Company M]; "charge them $50 \%$ of the real cost to build the first pilot of users. That's what I do; until now they are with me!" [company N].

"we exchange ideas and exchange feedback with customers ... during this [development] process"

customer's co-creational role [company C]; "If more than $85 \%$ of the people here like your product, what you have done, the way user experience and everything, then you say okay we have done a nice job" [company Q]. "next will be design. Design based on whatever requirements. After the signoff if customers agree, we go to the development" [company G]; "we have tools that can be shared together with customers. So, they know the list of milestones. So, each one of those milestones follow those schedules. Each one of the schedules ... customers will gain insight" [company A]; "we always do follow projects ... there will be a weekly project status update" [company A]; "I just engage the client on monthly bases or weekly bases" [company M].

"we completed the product, and then the user needs to accept it, they need to test every function" [company B]; "we will give it for user-acceptance test, and then if the customer want something fixed, then we can do it" [company J]; "and after that there will be training" [company G]; "we also do tutorial"

customer tester role [company S]; "normally we will do all the after-sale service" [company F]; "we will take up the feedback in a way which is helpful and aligned to [our] service" [company Q]; "they will usually report of the project to see what works, what doesn't work" [company L]; "we already have like few clients with more control, more feedback" [company N]. 
Table A6. Cont.

Main Emergent Themes

\section{Exemplary Quotations from Respondents}

"we progress stage by stage based on the needs, remember it always go back there" [company N]; "we get feedbacks, constant feedbacks from users and then we go and improve on our solutions" [company $\mathrm{S}$ ]; "we got all the data from there we have other features that we plan to develop" [company B]; "if you see my first version and until now it is different ... this is after a lot of people giving feedback"

customer initiator and [company N]; “you want to continually push things into that customer ... because someone else will inspirational role come and do it to your customer if you don't do it to them" [company D].

"So, find a problem, challenge your assumptions based on your findings and take feedback from the people and it may require from you to go back... It may require going back and try again. So, the iteration you have to make when you find out that whatever you thought that was a solution for the problem actually it is not true" [company U].

"it is important to understand customers' requirements because you cannot afford misunderstanding or miscommunication in any project implementation," [company K].

"we seek advice from customers and at the same time we do our self-brainstorming to basically complement each other in term of operation understanding. So, we exchanged ideas and exchanged feedback. During the process I would say we made the product more mature, and richer in terms of the features, in terms of the feedback, in terms of the user-friendliness" [company C].

the advantages of "seeking customers feedback can open up your mind, widen the horizon and more business engaging market actors opportunities for you" [company C].

"we get initial feedback, we give them wire frame or an idea of what the app can look like and then they can give feedback, then we will go back and fix it" [company J].

"and why we are successful? ... Because I like to take input from users all the time" [company N]. "You got to get that feedback all the time. Otherwise, if you are working in a perfect innovation in the corner, you going to tell people about it later! It doesn't work; the world moved on, or you missed it" [company D].

"one of the tools that I always use is called "talk to CEO". Clients can talk to me directly to give feedback.

digital technologyinitiation stage they come in here and they talk about whatever they need. They currently asked for a better postage calculation, so then I tell them within two weeks we going to do it" [company N]; "Big Data, we collect a lot of information ... then you catch it, analyze roughly, this will be the trend of next year" [company G]; "the database help create all the ideas" [company F].

"For example, if I open my phone, I have my app that can look at all the status by a dashboard. So, I can see all the information of my projects in the phone ... you do not need to come in the office. You do not need to call people and disturb them. You can just go in a dashboard or a system and see where the

digitally technologydevelopment stage project is ... I don't need to go and be present" [company M]; "we talk through skype and we talk through WhatsApp ... through emails if they need me and we are updated through these means" [company F].

digital technology- "after collecting the data from social media we already develop some motion learning algorithms to commercialization stage automatically find that for these pieces of the text; what is the sentiment of it? Is it positive or negative?" [company H]; "we market through Facebook, YouTube or any other media channel" [company F].

The cost reduction comes from the fact that we can automate a lot of things. So, a lot of it comes from removing inefficiency in the current [system] also" [company L]; “The product is actually the same cost all the time, just that digital things eliminate middlemen. With all these feasibilities, I mean it is very transparent and now ... once the confident is there you can see the volume is just exponential growth" [company O]; "If you have thousands of data, it is very difficult ... everything has to be digitalized ...

digital technology thus, easy to transport between partners and partners" [company P]; "based on big data you can predict benefits customer behavior the next month and based on those predictions ... you can tell what the next step will be to take to ... satisfy the customers in a better way, to create more revenue" [company H]; "most common thing is using data to make your decision" [company J]; "all these data ... at the end of the day you can use it for planning ... all these data can be analyzed. It can be analyzed then it can become business intelligent" [company C]; "data helps them make better decisions towards increasing the revenue and decreasing the cost of the company and creating more satisfaction for the customer and keep that customer" [company $\mathrm{H}$ ] 


\section{References}

1. Yoo, Y.; Henfridsson, O.; Lyytinen, K. Research commentary-The new organizing logic of digital innovation: An agenda for information systems research. Inf. Syst. Res. 2010, 21, 724-735. [CrossRef]

2. Lyytinen, K.; Yoo, Y.; Boland, R.J., Jr. Digital product innovation within four classes of innovation networks. Inf. Syst. J. 2016, 26, 47-75. [CrossRef]

3. Yoo, Y.; Boland, R.J., Jr.; Lyytinen, K.; Majchrzak, A. Organizing for innovation in the digitized world. Organ. Sci. 2012, 23, 1398-1408. [CrossRef]

4. Goncalves, D.; Bergquist, M.; Bunk, R.; Alänge, S. The Impact of Digitization on Contemporary Innovation Management. In Proceedings of the 25th Americas Conference on Information Systems (AMCIS), Cancun, Mexico, 15-17 August 2019.

5. Nambisan, S.; Wright, M.; Feldman, M. The digital transformation of innovation and entrepreneurship: Progress, challenges and key themes. Res. Policy 2019, 48, 103773. [CrossRef]

6. Barrett, M.; Davidson, E.; Prabhu, J.; Vargo, S.L. Service innovation in the digital age. MIS Q. 2015, 39, 135-154. [CrossRef]

7. Ebermann, C.; Piccinini, E.; Busse, S.; Leonhardt, D.; Kolbe, L.M. What Determines the Adoption of Digital Innovations by Digital Natives?-The Role of Motivational Affordances. In Proceedings of the 2016 International Conference on Information Systems (ICIS 2016), Dublin, Ireland, 11-14 December 2016.

8. Makkonen, H.; Komulainen, H. Explicating the market dimension in the study of digital innovation: A management framework for digital innovation. Technol. Anal. Strateg. Manag. 2018, 30, 1015-1028. [CrossRef]

9. Von Hippel, E.; Von Krogh, G. Crossroads-Identifying viable "need-solution pairs": Problem solving without problem formulation. Organ. Sci. 2016, 27, 207-221. [CrossRef]

10. Svahn, F.; Mathiassen, L.; Lindgren, R. Embracing Digital Innovation in Incumbent Firms: How Volvo Cars Managed Competing Concerns. MIS Q. 2017, 41, 239-253. [CrossRef]

11. Ahmad, T.; Van Looy, A. Business process management and digital innovations: A systematic literature review. Sustainability 2020, 12, 6827. [CrossRef]

12. Nambisan, S.; Lyytinen, K.; Majchrzak, A.; Song, M. Digital Innovation Management: Reinventing innovation management research in a digital world. MIS Q. 2017, 41. [CrossRef]

13. Leonhardt, D.; Haffke, I.; Kranz, J.; Benlian, A. Reinventing the IT function: The Role of IT Agility and IT Ambidexterity in Supporting Digital Business Transformation. In Proceedings of the 25th European Conference on Information Systems (ECIS), Guimarães, Portugal, 8-10 June 2017.

14. Urbinati, A.; Bogers, M.; Chiesa, V.; Frattini, F. Creating and capturing value from Big Data: A multiple-case study analysis of provider companies. Technovation 2019, 84, 21-36. [CrossRef]

15. Ciriello, R.F.; Richter, A.; Schwabe, G. From Process to Practice: Towards a Practice-based Model of Digital Innovation. In Proceedings of the38th International Conference on Information Systems (ICIS 2017), Seoul, Korea, 10-13 December 2017.

16. Lubik, S.; Garnsey, E. Entrepreneurial innovation in science-based firms: The need for an ecosystem perspective. In Handbook of Research on Small Business and Entrepreneurship; Edward Elgar Publishing: Cheltenham, UK, 2014.

17. Pellinen, A.; Ritala, P.; Järvi, K.; Sainio, L.M. Taking initiative in market creation-a business ecosystem actor perspective. Int. J. Bus. Environ. 2012, 5, 140-158. [CrossRef]

18. Moro-Visconti, R. Networking Digital Platforms and Healthcare Project Finance Bankability. Sustainability 2021, $13,5061$. [CrossRef]

19. Guo, Y.; Zhu, Y.; Chen, J. Business Model Innovation of IT-Enabled Customer Participating in Value Co-Creation Based on the Affordance Theory: A Case Study. Sustainability 2021, 13, 5753. [CrossRef]

20. Polykarpou, S.; Barrett, M. Why Place Still Matters in Digital Innovation: Organizing 3D Printing in a UK Hospital. In Proceedings of the 38th International Conference on Information Systems (ICIS), Seoul, Korea, 10-13 December 2017.

21. Huang, J.W.; Li, Y.H. Green innovation and performance: The view of organizational capability and social reciprocity. J. Bus. Ethics 2017, 145, 309-324. [CrossRef]

22. Ciriello, R.F.; Richter, A. Idea hubs as nexus of collective creativity in digital innovation. In Proceedings of the 36th International Conference on Information Systems (ICIS 2015), Fort Worth, TX, USA, 13-16 December 2015.

23. Liu, W.; Moultrie, J.; Ye, S. The customer-dominated innovation process: Involving customers as designers and decision-makers in developing new product. Des. J. 2019, 22, 299-324. [CrossRef]

24. Galvagno, M.; Dalli, D. Theory of value co-creation: A systematic literature review. Manag. Serv. Qual. 2014, $24,643-683$. [CrossRef]

25. Tao, F.; Sui, F.; Liu, A.; Qi, Q.; Zhang, M.; Song, B.; Lu, S.C.-Y.; Nee, A.Y.C. Digital twin-driven product design framework. Int. J. Prod. Res. 2019, 57, 3935-3953. [CrossRef]

26. Brannen, J. Mixing Methods: Qualitative and Quantitative Research; Routledge: London, UK, 2017.

27. Omery, A. Phenomenology: A method for nursing research. Adv. Nurs. Sci. 1983, 5, 49-64. [CrossRef]

28. Merleau-Ponty, M. Phenomenology of Perception; Routledge Kegan Paul: London, UK, 1962; p. 182.

29. Patton, M.Q. Qualitative Evaluation and Research Methods; SAGE Publications, Inc.: Los Angeles, CA, USA, 1990.

30. Clark, A.M. The qualitative-quantitative debate: Moving from positivism and confrontation to post-positivism and reconciliation. J. Adv. Nurs. 1998, 27, 1242-1249. [CrossRef] 
31. Malaysian SMEs Corps. SME Annual Report: Survey on SMEs in 2017/18. Available online: https://www.smecorp.gov.my/index. php/en/laporan-tahunan/3342-laporan-tahunan-pks-2017-18 (accessed on 5 August 2021).

32. OECD. Small, Medium, Strong. Trends in SME Performance and Business Conditions; OECD Publishing: Paris, France, 2017.

33. Nor, N.M.; Bahari, N.A.S.; Adnan, N.A.; Kamal, S.M.Q.A.S.; Ali, I.M. The effects of environmental disclosure on financial performance in Malaysia. Procedia Econ. Financ. 2016, 35, 117-126. [CrossRef]

34. Khin, S.; Ho, T.C. Digital technology, digital capability and organizational performance. Int. J. Innov. Sci. 2019, 11, 177-195. [CrossRef]

35. Ghezzi, A.; Balocco, R. Disclosing the role of IT Suppliers as Digital Innovation enablers for SMEs: A strategy analysis of the European IT Sales Channel. In Proceedings of the 49th Hawaii International Conference on System Sciences (HICSS), Koloa, HI, USA, 5-8 January 2016.

36. Hungler, B.P.; Beck, C.; Polit, D. Essentials of Nursing Research: Methods, Appraisal, and Utilization; Lippincott-Raven: New York, NY, USA, 1997.

37. Ames, H.; Glenton, C.; Lewin, S. Purposive sampling in a qualitative evidence synthesis: A worked example from a synthesis on parental perceptions of vaccination communication. BMC Med. Res. Methodol. 2019, 19, 26. [CrossRef]

38. Law, C.C.; Ngai, E.W. An empirical study of the effects of knowledge sharing and learning behaviors on firm performance. Expert Syst. Appl. 2008, 34, 2342-2349. [CrossRef]

39. Ngo, L.V.; O'Cass, A. In search of innovation and customer-related performance superiority: The role of market orientation, marketing capability, and innovation capability interactions. J. Prod. Innov. Manag. 2012, 29, 861-877. [CrossRef]

40. Miles, M.B.; Huberman, A.M. Qualitative Data Analysis: An Expanded Sourcebook; Sage: New York, NY, USA, 1994.

41. Cooper, H.E.; Camic, P.M.; Long, D.L.; Panter, A.T.; Rindskopf, D.E.; Sher, K.J. (Eds.) APA Handbook of Research Methods in Psychology, Vol 2: Research Designs: Quantitative, Qualitative, Neuropsychological, and Biological; American Psychological Association: Washington, DC, USA, 2012; pp. 57-71.

42. Ricœur, P. Heretical Essays in the Philosophy of History; Open Court Publishing: Chicago, IL, USA, 1996.

43. Willig, C. Interpretation in qualitative research. In The SAGE Handbook of Qualitative Research in Psychology; SAGE: Los Angeles, CA, USA, 2017; pp. 274-288.

44. Eisenhardt, K.M. Building theories from case study research. Acad. Manag. Rev. 1989, 14, 532-550. [CrossRef]

45. Vega, A.; Chiasson, M. A comprehensive framework to research digital innovation: The joint use of the systems of innovation and critical realism. J. Strateg. Inf. Syst. 2019, 28, 242-256. [CrossRef]

46. Barthel, P.; Hess, T. Are Digital Transformation Projects Special? In Proceedings of the 23rd Pacific Asia Conference on Information Systems (PACIS 2019), Xi'an, China, 8-12 July 2019.

47. Bhatnagar, N.; Gopalaswamy, A.K. The role of a firm's innovation competence on customer adoption of service innovation. Manag. Res. Rev. 2017, 40, 378-409. [CrossRef]

48. López-Cabarcos, M.Á.; Srinivasan, S.; Vázquez-Rodríguez, P. The role of product innovation and customer centricity in transforming tacit and explicit knowledge into profitability. J. Knowl. Manag. 2020, 24, 1037-1057. [CrossRef]

49. Psomas, E.; Kafetzopoulos, D.; Gotzamani, K. Determinants of company innovation and market performance. TQM J. 2018, 30, 54-73. [CrossRef]

50. Danarahmanto, P.A.; Primiana, I.; Azis, Y.; Kaltum, U. The sustainable performance of the digital start-up company based on customer participation, innovation, and business model. Bus. Theory Pract. 2020, 21, 115-124. [CrossRef]

51. Chang, W.; Taylor, S.A. The effectiveness of customer participation in new product development: A meta-analysis. J. Mark. 2016, 80, 47-64. [CrossRef]

52. Goyal, S.; Ahuja, M.; Kankanhalli, A. Does the source of external knowledge matter? Examining the role of customer co-creation and partner sourcing in knowledge creation and innovation. Inf. Manag. 2020, 57, 103325. [CrossRef]

53. Heim, G.R.; Mallick, D.N.; Peng, X. Antecedents and consequences of new product development practices and software tools: An exploratory study. IEEE Trans. Eng. Manag. 2011, 59, 428-442. [CrossRef]

54. Kawakami, T.; Durmuşoğlu, S.S.; Barczak, G. Factors influencing information technology usage for new product development: The case of japanese companies. J. Prod. Innov. Manag. 2011, 28, 833-847. [CrossRef] 